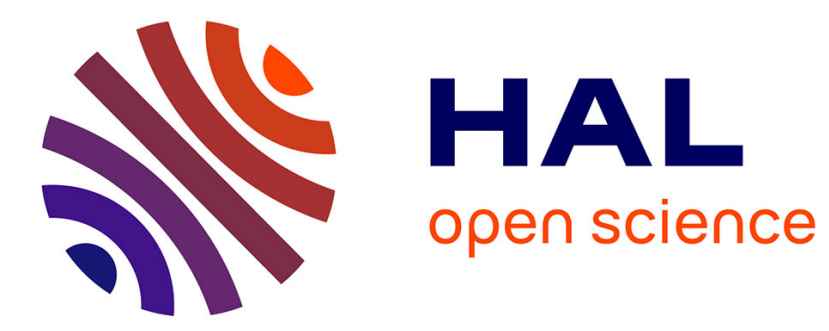

\title{
Household transitions to energy efficient lighting
}

Bradford Mills, Joachim Schleich

\section{To cite this version:}

Bradford Mills, Joachim Schleich. Household transitions to energy efficient lighting. Energy Economics, 2014, 46 (November 2014), pp.151-160. 10.1016/j.eneco.2014.08.022 . hal-01076005

\section{HAL Id: hal-01076005 \\ http://hal.grenoble-em.com/hal-01076005}

Submitted on 20 Oct 2014

HAL is a multi-disciplinary open access archive for the deposit and dissemination of scientific research documents, whether they are published or not. The documents may come from teaching and research institutions in France or abroad, or from public or private research centers.
L'archive ouverte pluridisciplinaire $\mathbf{H A L}$, est destinée au dépôt et à la diffusion de documents scientifiques de niveau recherche, publiés ou non, émanant des établissements d'enseignement et de recherche français ou étrangers, des laboratoires publics ou privés. 


\title{
Household Transitions to Energy Efficient Lighting
}

\author{
Bradford Mills $^{\mathrm{a}} *$ and Joachim Schleich ${ }^{\mathrm{a}, \mathrm{b}, \mathrm{c}}$ \\ August 2014 \\ ${ }^{\text {a }}$ Virginia Polytechnic Institute and State University, Blacksburg, Virginia, USA \\ *bfmills@vt.edu (corresponding author) \\ ${ }^{\mathrm{b}}$ Fraunhofer Institute for Systems and Innovation Research, Karlsruhe, Germany \\ ${ }^{\mathrm{c}}$ Grenoble Ecole de Management, France
}

\begin{abstract}
New energy efficient lighting technologies can significantly reduce household electricity consumption, but adoption has been slow. A unique dataset of German households is used in this paper to examine the factors associated with the replacement of old incandescent lamps (ILs) with new energy efficient compact fluorescent lamps (CFLs) and light emitting diodes (LEDs). The 'rebound' effect of increased lamp luminosity in the transition to energy efficient bulbs is analyzed jointly with the replacement decision to account for household self-selection in bulb-type choice. Results indicate that the EU ban on ILs accelerated the pace of transition to CFLs and LEDs, while storage of bulbs significantly dampened the speed of the transition. Higher lighting needs and bulb attributes like energy efficiency, environmental friendliness, and durability spur IL replacement with CFLs or LEDs. Electricity gains from new energy efficient lighting are mitigated by $23 \%$ and $47 \%$ increases in luminosity for CFL and LED replacements, respectively. Model results suggest that taking the replacement bulb from storage and higher levels of education dampen the magnitude of these luminosity rebounds in IL to CFL transitions.
\end{abstract}

Key words: energy-efficient lamps; household adoption; rebound effect 


\section{Household Transitions to Energy Efficient Lighting}

\section{INTRODUCTION}

Residential lighting technologies have shown dramatic increases in energy efficiency in recent years. Compact fluorescent lamps (CFLs) and light emitting diodes (LEDs) require about $80 \%$ and $85 \%$ less electricity compared to incandescent lamps (ILs) and last 6 and 26 times longer, respectively (EC 2011b, IEA 2012, CLASP 2013).1 Hence, widespread adoption of these technologies has the potential to significantly reduce household electricity consumption, which accounts for about $10 \%$ of residential electricity consumption in the EU (Bertoldi et al. 2012). The diffusion of energy-efficient light bulbs has been hampered, however, by several factors, including bulb size and shape (visual appearance), perceived lower lighting quality, limited dimmability, warm-up period before achieving full brightness, environmental and health concerns associated with toxic mercury in CFLs, and higher initial purchase costs (e.g. EC 2011a,b, de Almeida et al. 2013). Given high initial costs it may not be economically rational to replace ILs with energy-efficient bulbs in rooms where daily usage time tends to be short (e.g. Mills and Schleich 2010 and Frondel and Lehmann 2011). For instance, a bulb in the attic, storage room or bedroom where the daily usage time is less than 15 minutes may only pay-off the higher initial purchase cost after more than a decade.

In order to accelerate the transition to more energy-efficient lighting, several countries have implemented bans on imports and domestic sales of incandescent light bulbs since (IEA 2010). In

1 In an IL electric current runs through a wire filament and heats the filament until it glows. In a CFL, an electric current passes through a tube containing argon and a small amount of mercury vapor. This generates ultraviolet light that excites a fluorescent coating on the inside of the tube, which emits visible light. An LED is a semiconductor device that produces visible light when an electrical current is passed through it. Since efficacy varies with technology, manufacturer, voltage and wattage, figures on electricity savings can only be approximate. 
the EU, where ILs still accounted for more than 50\% of the residential lighting stock in 2009 (Bertoldi et al. 2012), Commission Regulation (EC) No 244/2009 imposed an immediate ban of non-clear incandescent lamps along with a gradual phase-out of other incandescent household bulbs. The ban was applied starting in September of 2009 with the highest wattage ILs ( $>=100 \mathrm{~W})$, and finishing in September of 2012 with the lowest wattage ILs $(<60 \mathrm{~W})$.

Little is known though about the role that the bulb ban has played in accelerating household transitions from ILs to energy efficient bulbs. Analyses of the international market for residential lighting suggest that in recent years many households were already making the transition from purchasing ILs to purchasing more energy-efficient CFL and LED bulbs and that the trend was even accelerating (e.g. IEA 2010, McKinsey 2012). Only two decades ago the vast majority of residential light bulbs were ILs. For example, in 1995 the IL share of all bulbs in the average household in the EU was about 85\% (VITO 2009). By 2007 this share dropped to 54\%, while the stock shares of halogens and CFLs were by then $23 \%$ and $15 \%$, respectively. Similarly the market share of ILs in the EU decreased from $61 \%$ in 2006 to $41 \%$ in 2010 . For the same period, the market share of CFLs increased from 15\% to 23\% (Bertoldi et al. 2012, IEA 2012). More recently, LEDs have rapidly entered the residential light bulb market, and their prices have declined markedly (McKinsey (2012). Clearly the ban did not spur transitions among early adopters, but the ban may have forced lagging households to also transition to energy efficient bulbs. On the other hand, households with strong preferences for ILs may have stockpiled ILs prior to implementation of the ban on specific bulb types ${ }^{2}$. Likewise, households often store bulbs to prevent extended loss of lighting services should a bulb suddenly break or in order to lower transaction costs related to purchasing bulbs. Such storage of ILs will slow down the transition towards more energy-efficient bulbs and delay the impact of a ban.

2 Such stockpiling was observed in several European countries in the first half of 2009, notably Germany (Kanter 2009; Spiegel Online International 2009). 
Slow diffusion may not be the only constraint inhibiting electricity savings from energy efficient bulbs. Savings may be lower than expected from a strictly engineering-economic assessment due to 'rebound effects' (e.g. Khazzoom 1980, 1987, 1989; van den Bergh 2011; Brookes 1990; Frondel et al. 2008, 2012; Greening et al. 2000; Madlener and Alcott 2009; or Sorrell 2007). Since purchasing energy-efficient light bulbs means lower costs of lighting services, households may respond by letting bulbs burn longer, using more bulbs for additional lighting services, or increasing the luminosity of bulbs purchased, thereby increasing the demand for lighting services. 3 In addition to this direct rebound effect, indirect and economy-wide rebound effects may also exist. Indirect rebound effects reflect additional energy use associated with higher expenditures for other goods and services based on cost savings. Macroeconomic (or economy-wide) rebound effects are typically the result of productivity improvements and radical innovations resulting in additional applications of energy-using technologies and economic growth (i.e. a macroeconomic growth effect). Income effects and economy-wide rebound effects associated with lighting are typically, in the short to medium term, small since the share of lighting in total electricity consumption and the expenditures for lighting as a fraction of disposable income are rather small (e.g. Fouquet and Pearson 2012, Chitnis et al. 2013). Several empirical studies find direct rebound effects of energy efficient lighting, including Greening et al. (2000), de Almeida (2008), Chitnis et al. (2013), and Schleich et al. (2014), but with the exception of Fouquet and Pearson (2006, 2012), and Schleich et al. (2014), these studies focus on the rebound effects from longer burn time only. In particular, relying on data for several hundred years, Fouquet and Pearson $(2006,2012)$ find that total consumption of lighting services increased substantially over time in response to cheaper and better lighting services and in response to growing

3 Some increases in household welfare likely occur from the increased duration or intensity of lighting use. 
incomes. 4 Schleich et al. (2014) use the same dataset as this study and calculate the rebound effects for energy efficient lighting in terms of both burn-time and luminosity. 5 However, the factors that drive household choice of energy efficient bulbs and the factors associated with increases in luminosity are not explored.

Studies exploring the relation between household adoption of energy efficient bulbs and socio-economic factors include Scott (1997) and di Maria et al. (2010) for Ireland, Kumar et al. (2003) for India and Mills and Schleich (2010) for Germany, but only Kumar et al. (2003) find a strong positive correlation (for income and education), while di Maria et al. (2010) highlight the role of environmental awareness. Existing studies though are based on data collected either in the 1990s or early 2000s and CFLs and LEDs have improved markedly as substitutes for ILs since then. Similarly, no empirical analysis has been undertaken on the actual impact of the EU ban, particularly when accounting for the pre-ban existence of a market shift away from ILs.

In this paper, we examine three fundamental questions related to the efficacy of the EU ban on ILs. 1) Did the ban appreciably increase the rate of adoption of energy efficient CFL and LEDs? 2) What other factors are associated with the switch from ILs to energy efficient lamps? 3) What are the factors associated with increases in lamp luminosity observed with the changeover to energy efficient lamps?

These questions are addressed using a 2012 representative survey with more than 1,600 documented choices of how private households in Germany replaced ILs. The paper represents, to our knowledge, the first attempt to analyze factors associated with household decisions to

4 For example, lighting demand increased by a factor of 500 over the last three centuries in the UK. Fouquet and Pearson (2012) estimate the own price elasticity of lighting demand for the early twentyfirst century in the UK at around -0.5. While this may only be a crude estimate for the size of the rebound effect in lighting demand assuming unsatiated lighting needs, it provides some evidence that the effect is not negligible (see also Borenstein 2013).

5 Schleich et al. (2014) employ discrete indicators of increases and decreases in burn time. But recall data on changes in burn-time are inherently more difficult to collect and this study does not attempt to examine factors associated with those discrete changes. 
adopt energy efficient bulbs after the implementation of the EU ban and to document factors associated with concurrent changes in bulb luminosity.

The remainder of the paper is organized as follows. Section 2 presents the papers theoretical and empirical framework. Section 3 presents the statistical model and data. Section 4 presents the results and Section 5 concludes and distils policy implications.

\section{THEORETICAL AND EMPIRICAL FRAMEWORK}

\subsection{Theory}

A utility maximizing household needs to replace a IL. The household makes two choices: 1) what bulb type to replace the initial IL with and 2) the wattage of the replacement bulb relative to the initial IL bulb. Assume that household utility associated with bulb replacement can be captured from net income after replacement, $y$, and lighting luminosity $L(\bullet)$ that has a bulbtype $i$ specific relationship with wattage, $w$, represented as $L^{i}(w) .6$

$U\left(y, L^{i}(w)\right)$ where $i=\mathrm{IL}, \mathrm{CFL}, \mathrm{LED}$.

Net income after replacement depends on base income, $y^{0}$, bulb-type and wattage specific costs of purchase, $B^{i}(w)$, and bulb-type specific variable costs of bulb use, $C^{i}(w)$.

$$
y=y^{0}-B^{i}(w)-C^{i}(w) .
$$

Given a bulb type, maximization of utility subject to the income constraint yields the optimal choice of bulb wattage $w^{*}$ where

$$
\frac{\partial U}{\partial L^{i}\left(w^{*}\right)} \frac{\partial L^{i}\left(w^{*}\right)}{\partial w^{*}}=\frac{\partial U}{\partial y}\left[\frac{\partial B^{i}\left(w^{*}\right)}{\partial w^{*}}+\frac{\partial C^{i}\left(w^{*}\right)}{\partial w^{*}}\right\rfloor
$$

\footnotetext{
6 Utility from all other goods not influenced by the bulb decision is assumed constant, as is bulb burn time.
} 
The marginal utility of the luminosity associated with increased wattage equals the marginal utility of income associated with the variable and fixed costs of the increased bulb wattage.

In choosing bulb type, the household chooses the highest ratio of marginal utility of luminosity-wattage to marginal costs:

$$
\frac{\frac{\partial U}{\partial L^{i}\left(w^{*}\right)} \frac{\partial L^{i}\left(w^{*}\right)}{\partial w^{*}}}{\frac{\partial B^{i}\left(w^{*}\right)}{\partial w^{*}}+\frac{\partial C^{i}\left(w^{*}\right)}{\partial w^{*}}}>\frac{\frac{\partial U}{\partial L^{k}\left(w^{*}\right)} \frac{\partial L^{k}\left(w^{*}\right)}{\partial w^{*}}}{\frac{\partial B^{k}\left(w^{*}\right)}{\partial w^{*}}+\frac{\partial C^{k}\left(w^{*}\right)}{\partial w^{*}}} \quad \forall k
$$

The marginal costs in the denominator highlight the tradeoffs households face in IL replacement choice, as upfront costs increase from ILs to LEDs while variable costs decrease:

$$
\frac{\partial B^{I L}(w)}{\partial w}<\frac{\partial B^{C F L}(w)}{\partial w}<\frac{\partial B^{L E D}(w)}{\partial w} \text { and } \frac{\partial C^{I L}(w)}{\partial w}>\frac{\partial C^{C F L}(w)}{\partial w}>\frac{\partial C^{L E D}(w)}{\partial w} .
$$

Clearly, an increase in bulb efficiency $\frac{\partial L^{i}\left(w^{*}\right)}{\partial w^{*}}$ or a decrease in marginal fixed costs $\frac{\partial B^{i}}{\partial w^{*}}$ or variable costs $\frac{\partial C^{i}}{\partial v^{*}}$ at the optimal wattage will make a household more likely to adopt a bulb type. Similarly the natural tendency for increased bulb efficiency to lead to increased luminosity is apparent in equation (1), as households will indulge in greater luminosity with part of their costsavings. ${ }^{7}$

Three other implications for bulb choice are worth noting from the model. First, some households (particularly with early generations of CFLs) prefer the light quality of ILs. In this case $\frac{\partial U}{\partial L^{I L}}>\frac{\partial U}{\partial L^{C F L}}$ for a given level of luminosity and CFLs will need differential cost-savings to overcome light quality preferences. Second, households may have incomplete information, particularly with respect to the efficiency of bulb types, $\frac{\partial L^{i}(w)}{\partial w}$, and the variable costs, $\frac{\partial C^{i}(w)}{\partial w}$. Generally, household information on new bulb types is expected to be less complete than infor-

7 Assuming non-satiation in lighting needs. 
mation on the initial IL bulb. Adoption of the energy-efficient bulb types will be deterred if efficiency gains are underestimated or if the probability of high levels of gains is discounted due to uncertainty. 8 Households can reduce information uncertainties through research on bulb performance, however such research is costly to the household and will further raise the effective upfront costs of CFLs and LEDs relative to ILs. Third, bulb purchase and use costs occur over different timeframes. Thus, individual time preferences are likely to also influence bulb choice. Specifically, individuals with high implicit discount rates will be more attracted to continue to use ILs, while those with low implicit discount rates will be more attracted to the lower long-run costs of CFLs and LEDs.

\subsection{Empirical Framework}

The econometric model is specified in light of the above household decision framework. Two choice equations are specified; the first governing bulb-type choice and the second governing luminosity choice. One would expect that households would be more likely to replace bulbs in 2012 with CFLs and LEDs than in 2010 or 2011, as the market share has trended towards CFLs and LEDs. Time trends in bulb uptake are also likely to be affected by the implementation on the IL ban. The impact of the IL ban is inferred through a 'bantime' interaction term between 2012 replacement and initial ILs classified as greater than 60W. This interaction term is employed because this group of bulbs is certain to be subject to the IL ban at the time of the replacement, as the survey data is from May and June 2012 and the ban on less than 60W bulbs was implemented in September 2012. If the ban is effective, the change in the propensity to replace these banned bulb types with CFLs and LEDs should be greater than the change in propensity in 2012 for other bulb types not subject to the ban. It is also possible that some $60 \mathrm{~W}+$ ILs replaced in 2010 and 2011 were also subject to the ban, as were some 60W bulbs in 2012 . Thus, the 'ban-

8 Although Allcott, Mullainathan, and Taubinsky (2012) find that providing households with economic information on CFL bulb efficiency relative to ILs does not change bulb purchase probability. 
time' variable should be seen as a lower bound measure of the impact of the IL ban on bulb replacement choice.

Concerns about the accuracy of recall of pre-2012 bulb replacements and reliance on changes in transition propensities from pre-2012 period to identify the impact of the EU ban are warranted. The questionnaire design tried to address these concerns by only considering the most recent bulb switch, by showing pictures of bulbs as part of the survey, and by allowing participants to opt out of responding to bulb replacement questions. It is also noting that errors associated with a longer recall period for time of last bulb replacement would have to be biased toward miss-stating transitions to CFLs and LEDs in the higher initial IL bulb wattage categories relative to the $60 \mathrm{~W}$ and lower categories, and there is no strong a priori reason to believe that this would be the case.

As discussed, many households may have stored IL bulbs for use after the ban. Therefore, taking a replacement bulb from storage should strongly decrease the probability of bulb replacement with an energy-efficient CFL or LED. Similarly, bulbs from storage are more likely to be of similar luminosity if both the initial bulb and the replacement are ILs.

Location and intensity of use of bulbs will have a large impact on both bulb-type choice and luminosity-wattage choice. Bulbs that are designated for main lighting needs are likely to be used more intensively and thereby generate greater variable cost savings for CFLs and LEDs relative to ILs.9 'Main' bulbs are, thus, more likely to be replaced with CFLs and LEDs than are bulbs used for secondary lighting. Similarly, the marginal utility of luminosity may be greater for 'main' bulbs, which will make households more likely to increase bulb luminosity in response to variable cost savings for main lighting than for secondary lighting when replacing a IL with a

9 Specifically, 'Main lighting' reference to use of the light bulb as the main source of lighting, as opposed to use for side lighting or background lighting. 
CFL or a LED. 10 The fact that marginal variable costs increase less with luminosity equivalent wattage for CFLs and LEDs will also tend to increase the relative magnitude of the rebound effect for main lighting.

The room in which the bulb is placed is also likely to impact bulb usage. As with 'main' lighting, households may be more likely to replace ILs with CFLs and LEDs in high lighting-use rooms like living rooms and kitchens and may be more likely to upgrade wattage in these rooms due to greater utility from increased lighting and larger marginal variable cost savings.

The literature frequently identifies rental units as less likely to adopt energy efficient technologies as benefits may not accrue to landlords. However, Mills and Schleich (2010) find renting does not significantly influence CFL adoption in German households. But LEDs have a much longer life and this may deter renter investments if renters are more mobile than homeowners and expect to move within several years. Renting is, however, unlikely to have a large impact on luminosity choice and is excluded from that equation.

Preferences for bulb attributes may also influence bulb type choice and luminosity decisions. In the survey respondents were allowed to choose up to three criteria (of ten listed) that they felt were most important in the choice of a bulb (translation of full question provided in table A.1). Six criteria - price, quality, electricity use, durability, environmental friendliness, and dimmable - are included in the bulb type choice equation specification. 11 The same criteria, except for dimmable, are also included in the luminosity choice equation. Those who list price as an important criteria may be less likely to replace ILs with initially more expensive CFLs or LEDs. An emphasis on price as a bulb criteria may also deter luminosity increases if it is indicative of cost consciousness.

10 Transitions to CFL and LED bulbs may also relieve luminosity constraints from restrictions of IL bulb wattage, particularly in main lighting fixtures.

11 The criteria producer/ brand, form/ shape, convenience of disposal, and rating in test reports were excluded from the analysis. 
Stating bulb 'quality' as an important attribute may deter replacement with CFLs, as ILs are felt by some to produce higher quality lighting. If quality is an important attribute to bulbs, households may also be less likely to invest in increased wattage for CFLs, as they will derive less utility from increased CFL luminosity than from increases under other bulb types. On the other hand if 'electricity use' is stated as an important bulb attribute, households may be more likely to place an emphasis on variable cost savings and switch to energy efficient bulbs - particularly very energy efficient LEDs. How stated importance of energy efficiency in bulbs may influence luminosity changes is left as an empirical question. Emphasis on electricity conservation may deter luminosity increases with more efficient bulbs. On the other hand, respondents may have been deterred from increasing luminosity previously with less efficient ILs and respond more vigorously in fulfilling unsatiated lighting needs. Similarly, listing durability as an important attribute implies an emphasis on long-term costs of the bulb, rather than just up front purchase price. Thus, durability is expected to be associated with an increased propensity to replace ILs with CFLs, and a very high propensity to replace ILs with long lasting LEDs.

The impact on IL replacement of stating 'environmental friendliness' as an important bulb attribute is less clear. The mercury found in CFLs is an environmental concern, which may deter adoption in favor of ILs. However, CLFs and LEDs have significant environmental benefits related to electricity savings. The net outcome of these different environmental attributes is an empirical question. In terms of changes in wattage, environmental concerns may temper household willingness turn part of their electricity savings into increases in luminosity. However, again, they may also respond by meeting previously restrained lighting needs. Dimmable CFL and LED bulbs are much more expensive, and reviews on performance are mixed (CLASP 2012), thus emphasis on dimmability as a bulb criteria is expected to deter the replacement of ILs with CFLs and LEDs. 
Lighting fixtures and accessories are rapidly evolving to accommodate the small size and low heat output of LEDs. Thus replacement of the whole lamp-set, instead of just the bulb, may foster transitions to energy saving LEDs. The impact of lamp-set replacement on CLF uptake is less clear a priori. But households may be more likely to increase wattage as part of their investments in lighting needs that require lamp replacement, particularly in the transition to LEDs, as fixtures sometimes list constraints on bulb wattage.

Household characteristics may also influence both bulb type and luminosity choice. Higher levels of education are usually associated with more rapid adoption of energy efficient technologies, as individuals with higher levels of education are able to more rapidly gain and process information on the costs and benefits of new technologies. Further, more educated individuals are likely to have higher incomes and be less financially constrained by the high up-front costs of energy efficient bulbs. The potential impact of education on luminosity choice is unclear. Highly educated individuals should be better able to determine the correct luminosity equivalent wattage of CFL and LED bulbs which would deter luminosity increases. However, more educated individuals have associate higher incomes that may make them willing to indulge in higher bulb luminosity upon replacement. Household member age may also impact bulb replacement decisions; 'young' households (with heads between 16 and 26) may be more financially constrained and less willing or able to pay high upfront costs for CFL and LED bulbs. On the other hand, 'elderly' household members 65 or over are generally more reluctant to change technologies and, thus, may also be more reluctant to replace ILs with CFLs or LEDs. The elderly may be more set in their lighting habits, and less likely to increase bulb luminosity upon bulb replacement, particularly for IL to IL replacement. The impact of gender on bulb type and wattage decisions is left as an empirical question. However, larger households may be expected to use bulbs more intensively, thus households of more than two persons 'twoplus' might be more likely to adopt energy efficient bulbs as the payback time will be shorter with higher usage. 


\section{METHODS AND DATA}

\subsection{Econometric Model}

As mentioned, the household chooses the bulb type with the highest marginal utility of luminosity to bulb marginal cost ratio. Denoting this ratio in the statistical model $y^{B^{*}}$, $y_{i}^{B^{*}}>\max \left(y_{j}^{B^{*}}\right) \quad$ for $j \neq i$. The observed choice of bulb-type $i$ can be modelled a linear function of observable covariates, $z$, and a random error component by multinomial logit.

$$
y^{B}=z \gamma+\eta
$$

Change in bulb luminosity, $y^{L}$, can also be modelled as a linear function of model covariates, $x$, and an error component.

$$
y^{L}=x \beta+u
$$

However, change in luminosity is only observed for the bulb-type with the highest marginal utility of luminosity to marginal bulb costs ratio, leading to highly selected samples of observed household change in bulb luminosity choices. As Heckman (1979) shows, the error term in equation (4) can be conditioned on the probabilities of selection of the alternative bulb types in order to correct for this sample selection bias. Two correction methods are employed that use the multinomial logit in equation (3) to generate Heckman-type selectivity correction terms. The first is the Dubin and McFadden (1984) selectivity correction estimation method. The method places no restrictions on the covariances of the bulb-type choice equation and the bulb-type specific luminosity choice equations by including selectivity correction terms for all three bulb-type choices in each luminosity choice equation. The second is the well-established Lee (1983) method that includes only one selectivity correction term based on the choice probabilities of the observed outcome. The Lee method is parsimonious and, thus, well-suited for relatively small 
samples of observed choice outcomes like those in the current study. However, parsimony comes at the cost of strong implied restrictions on the correlations between alternative bulb choices and luminosity choice. Following Bourguignon, Fournier, and Gurgand (2007), the restriction that the covariances sum to one in the Dubin and McFadden estimator is also dropped, as this variation of the sample selection correction method performs best in Monte Carlo simulations with moderate sample sizes similar to those in the current study. The 2012 replacement and banned in 2012 indicators variables, along with the rented residence and stated importance of dimmable bulb indicators are excluded from the luminosity change equation for model identification. Standard errors are generated based on bootstrapping with replacement at $\mathrm{N}=500$. Separate change in luminosity equations for the three replacement bulb types are also estimated by OLS without correction for selectivity for comparison.

\subsection{Data Description}

A representative survey of 6,409 households in Germany was carried out in May and June of 2012. The survey was implemented as a computer based questionnaire within an existing panel, where participating households were equipped with a visual interface (e.g. photographs of different bulb types were shown). Around $90 \%$ of households stated that they had at least one energy efficient light bulb installed in their home. About three-fourths of the households remembered when they last replaced a light bulb. Further, to limit recall bias in self-reported data only observations where the replacement occurred in 2012 (75\%) or in 2011/2010 (25\%) are retained. This leaves 4,061 events involving replacement decisions, either for a single bulb or for replaced lighting fixture. The vast majority of the new bulbs replaced a broken or burned out bulb (86\%), however $7 \%$ of new bulbs replaced a bulb that was not broken, and 5\% were part of a replacement fixture.

Table 1 presents these transitions by initial and replacement bulb type for all bulbs (broken and burned out, not broken, and fixture replacements). Almost half of the initial bulbs are ILs 
(44\%), this stems both from ILs prevalence of use and from the fact that ILs have shorter lifespans. CFLs represent 30\% of initial bulbs, while Halogens and LEDs represent $23 \%$ and 3\% percent of initial bulbs, respectively. Most consumers (71\%) maintained the same type of bulb when replacing a bulb (e.g. a IL is replaced with a IL). Of the $29 \%$ who did change bulb types, over two-thirds switched from an IL to another type of bulb. On the other hand, consistent with the general movement towards more energy efficient bulbs, less than 10 percent of these reported transitions were from an IL to a halogen lamp. 12 The remainder of the empirical analysis in the paper focuses on the replacement decisions of 1,714 households who initially had ILs and either maintained a IL (58\%) or replaced a IL with a CFL (35\%) or a LED (7\%).

The second dependent variable of interest in the analysis is the change in bulb luminosity associated with bulb replacement. In the survey households were asked about the wattage of both the replaced bulb and the new bulb.13 Five different wattage categories were given, with the categories being specific to the wattages commonly associated with each bulb type. Luminosity was then calculated on a per bulb per wattage basis with standard figures from the literature.

There are 1,660 observations with luminosity data for both the initial and replacement bulb. These observations are used to calculate the ratio of the luminosity of the new bulb to the old bulb (fluxratio). The sample average is 1.10 , indicating a $10 \%$ increase in luminosity on average with bulb replacement. However, the change in luminosity differs by new bulb type. Those who replace the IL with another IL have no statistically significant change in calculated luminosity (2\%), while households who replace the IL with a CFL and a LED have significant calculated increases in luminosity of $25 \%$ and $47 \%$, respectively. These descriptive statistics suggest a very significant rebound in terms of lighting intensity with the transition from ILs to energy efficient

12 For this reason, halogen bulbs are not included in the empirical analysis.

13 Bulb wattage rather than luminosity was asked, because households are more familiar with wattage and, unlike luminosity, wattage appears on the bulb (as well as on the package). 
lamps. One concern is that luminosity increases may arise simply from differences in common wattage categories for ILs, CFLs, and LEDs. However, analysis of wattage category specific transitions suggests common wattage category differences across bulb types may not be driving observed luminosity increases. 14 The factors associated with the magnitude of the observed rebound effect are further explored in the multivariate analysis.

Table 2 provides descriptive statistics on the dependent and independent variables used in the analysis of bulb transition choices and change in luminosity choices. Sample sizes for the replacement bulb choice and luminosity choice equations differ slightly due to missing data on the wattage of the initial or replacement bulb, so descriptive statistics are presented for both samples.

Of note, the 'bantime' variable identifies $12 \%$ of the initial ILs that were replaced in 2012 and were certain to have been subject to the ban. On the other hand, over $60 \%$ of bulbs came from storage rather than direct purchase, which would mitigate the impact of the ban.

Two-thirds of initial bulbs were used for main lighting of rooms, as opposed to background or side lighting. Around 28\% percent of initial ILs were located in the living or dining room, while $19 \%$ were in hallways, $16 \%$ were in bathrooms, $12 \%$ were in the kitchen, $9 \%$ were in the bedroom, and $16 \%$ were for child rooms, outdoors, and other rooms.

14 For example, the most frequent bulb transitions in the sample involve initial 40W and 60W ILs to CFLs. The equivalent CFL for a $40 \mathrm{~W}$ IL is either $7 \mathrm{~W}$ or $8 \mathrm{~W}$ depending on technology, manufacturer, etc. Since $7 \mathrm{~W}$ and $8 \mathrm{~W}$ CFLs are in the same category in our study, they are both considered to have the same luminosity (350 lumens) as a $40 \mathrm{~W}$ IL. $3 / 4$ of $40 \mathrm{~W}$ bulbs entail switches in these CFL categories, and they do not contribute to observed increases in luminosity. The remaining $25 \%$ of $40 \mathrm{~W}$ switches involve transitions to CFLs with clearly higher luminosity levels. For a 60W IL, the equivalent CFL would be either $11 \mathrm{~W}$ or $12 \mathrm{~W}$. The share of switches of $60 \mathrm{~W}$ ILs into these two CFL wattage categories and both approximately $40 \%$, suggesting little bias for calculated changes in luminosity. The remaining $20 \%$ of initial 60W IL switches involve transitions to CFL wattage categories with clearly higher luminosity levels. 
In terms of bulb purchasing criteria, energy efficiency, price, durability, and quality were most important criteria for bulb choice listed by respondents, while environmental friendliness and dimmability were far less frequently listed as important criteria.

Turning to the personal characteristics of respondents, approximately $28 \%$ of the respondents are in the baseline low education group with a high-school or lower level of education, $48 \%$ are in the middle group technical school group, and 30\% have a University degree. Females represent $40 \%$ of the respondents in the sample and most respondents are middle-age (around 5\% are young households between and around 18\% are elderly households). Single individuals represent $28 \%$ of respondents, while $42 \%$ of respondents live in two-person households, and $30 \%$ live in households containing more than two persons. Around $45 \%$ of households in the sample rented their house.

\section{RESULTS}

\subsection{Replacement Bulb-Type Choice}

Multinomial model estimation results for the choice of bulb-type equation are presented in table 3 for all households with the observed replacement of a bulb or fixture $(\mathrm{N}=1,714) .15 \mathrm{~Pa}-$ rameter estimates are reported as relative risk ratios, with IL to IL replacements as the base category. 16 For the 2012 year indicator variable the estimated relative risk ratio $(0.585)$ in column 1 indicates that there is actually a significant decrease in the relative 'risk' or relative likelihood of IL replacement with a CFL when the bulb is replaced in 2012 compared to when the bulb is re-

15 Similar results are found if the model is estimated using the slightly smaller sample $(\mathrm{N}=1,660)$ of households reporting the wattage of both the initial and the replacement bulb.

16 A relative risk ratio of 1.0 would indicate that there is no change in the risk of one bulb-type choice compared to another type with a change in the variable. 
placed in prior years. 17 A similar result is found for IL to LED replacements in column 3 (with a 0.591 relative risk ratio). The results seem to be at odds with market trends that clearly indicate a movement over time toward CFL and LED bulbs. However, care should be taken in the interpretation of this trend parameter. ILs burn out far more quickly than CFLs or LEDs, thus it may be that households with a higher remaining share of ILs are more likely to have replaced a bulb recently (i.e. in 2012). However, these households may have a higher share of ILs due to a higher propensity to replace ILs with ILs.

On the other hand, the 'bantime' parameter estimates - indicating bulbs replaced in 2012 that were definitely subject to the EU ban at the time of replacement - have the expected sign. The relative risk of IL replacement with a CFL increases by a factor of 1.8, while the relative risk of replacement with a LED increases by a factor of 3.2 when the wattage of the initial IL made it subject to the ban in 2012. It is also worth noting that the sign and magnitude of the 'bantime' parameter estimates remain largely unchanged if IL bulbs in the next wattage category with initial wattages between $41 \mathrm{~W}$ and $60 \mathrm{~W}$ are also included in the banned bulb group. A significant share of bulbs in this next group are presumably $60 \mathrm{~W}$ bulbs and would have also been included under the ban in 2012. As expected, retrieval of the replacement bulb from storage shows a strong negative association with the movement towards energy efficient bulbs. The relative risk of IL replacement with a CFL decreases by a factor of 0.2 , while replacement with a LED decreases by an extremely strong factor of 0.03 .

Turning to other variables associated with type of bulb use, the variable 'lamps' indicates that for households that replace a lamp fixture along with the bulb the relative risk of choosing a CFL compared to an IL increases by a factor of 2.8. Similarly, the relative risk of choosing a LED increases by a factor of 4.0 with lamp fixture replacement. Thus, lamp fixture replacement is

17 In the presentation of the results, 'significant' refers to the conventional $p=0.05$ level unless a specific level is noted. 
strongly associated with increased choice of energy efficient bulbs. As expected, the relative risks of IL replacement with a CFL and with a LED both increase when the bulb is used for 'main' lighting ( $p=0.10)$; the increases are by factors of 1.4 and 1.7 , respectively. However, the room in the households where the bulb is used has little impact on the relative risk of replacement with energy saving bulbs. In fact the only significant estimate is a decline in the risk of IL replacement with an LED in 'other rooms' relative to the base living room category by a factor of 0.4 . Renting also has no significant impact on bulb choice.

Stated importance of several bulb attributes show a significant association with bulb choice. Surprisingly, price does not matter. But in self-reporting their criteria for decisionmaking respondents may be reluctant to list price or financial concerns more broadly as of primary importance. On the other hand, listing lighting 'quality' as an important bulb attribute increases the relative risk of IL replacement with a LED by a factor of 1.7. As expected, listing electricity use as an important bulb attribute strongly increases the relative risk of CFL adoption by a factor of 2.5 and has an even stronger impact on LEDs adoption, increasing the relative risk by a factor of 7.8. Thus, consumers with strong preferences for electricity savings in lighting appear to recognize the superior performance of LEDs. Relative risks of CFL $(p=0.10)$ and LED adoption also increase marginally when durability is listed as an important bulb attribute, while listing dimmability as an important bulb attribute increases the relative risk of IL replacement with a LED $(p=0.10)$. Listing environmental friendliness increases the relative risks of IL replacement with a CFL and with a LED by factors of 2.4 and 3.0, respectively. Thus, disposal concerns associated with CFLs do not appear to deter adoption among households with preferences for environmentally friendly bulbs.

In terms of household characteristics, education has no significant impact on IL bulb replacement choices. However, female survey respondents are less likely to replace ILs with LEDs, with the relative risk decreasing by a factor of 0.6. Similarly, young respondents between 
16 and 26 years of age are less likely to replace ILs with CFLs $(p=0.10)$ or LEDs $(p=0.10)$ compared to respondents between 27 and 65 years of age, with relative risks decreasing by factors of 0.6 and 0.4 , respectively, for the two bulb types. Older respondents (over 65 years of age) show a decreased relative risk of CFL adoption $(p=0.10)$, but no change in the propensity to replace ILs with LEDs. Finally larger (more than two person) households show an increased relative risk (by a factor of 1.9) of replacing ILs with LEDs, this may stem from higher lighting demands in larger households.

\subsection{Change in Luminosity}

Results for the sample-selectivity corrected IL to IL, IL to CFL, and IL to LED change in luminosity equations using the Dubin-McFadden selectivity correction method are presented in table 4 for the slightly smaller sample $(\mathrm{N}=1,660)$ of household that report wattage of both the initial and replacement bulb. Overall, the statistical models associated with the luminosity changes for all three bulb transitions have very low predictive power. In fact, F-tests indicate that overall variables in the IL to IL change in luminosity model and the IL to CFL change in luminosity model have significant explanatory power, but variables in the IL to LED model do not. Reported adjusted R-squared statistics for the three models are also low.

Descriptive statistics indicate no overall change in the bulb luminosity ratio for IL to IL bulb transitions. However, a number of individual covariates are significantly associated with the luminosity ratio. Taking a bulb from storage is associated with a decrease in the tendency to increase bulb luminosity, with an estimated 18 percent lower luminosity ratio than when a new IL bulb is bought from a store. As expected, when a bulb is used for main lighting, the luminosity of the new IL is, on average, 6 percent brighter. Bulb location in the household, however, is not associated with changes in luminosity.

Surprisingly, two stated important attributes of bulbs, energy efficiency and environmental friendliness, show a positive association with the bulb luminosity ratio in the IL to IL model. 
One might speculate that stated energy efficiency and environmental preferences are weak if one decides to replace an IL bulb with another IL. The bulb luminosity replacement ratio is found to be lower among younger ( 16 to 26 years of age) respondents $(p=0.10)$. Finally, the IL to CFL selectivity correct coefficient (m12) is significant, implying that there is significant correlation between the unobserved heterogeneity in the IL to CFL bulb-type choice equation and the unobserved heterogeneity in the IL luminosity choice equation.

The descriptive statistics also indicate that the average increase in bulb luminosity when moving from an IL to a CFL is 23 percent. The IL to CFL luminosity choice equation estimates indicate that there is a very strong decrease in bulb luminosity change when the initial bulb is an IL and the replacement is a CFL taken from storage instead of bought at a store. Individuals who plan ahead and store new CFL bulbs for replacement may take more time to establish the equivalent luminosity. There is, on the other hand, an increase in luminosity when the respondent indicates that energy efficiency is an important bulb attribute. In this case the result is understandable and consistent with the rebound effect, as respondents who place an emphasis on energy savings may be willing to indulge more in luminosity to meet unsatiated lighting demands when they use an energy efficient CFL replacement bulb. Education also appears to influence CFL luminosity choice ( $p=0.10$ ), as luminosity of the CFL relative to the initial IL decreases 23 percent when the respondent has a university education as opposed to high school or less - essentially offsetting the observed average luminosity increase in IL to CFL transitions. The result is consistent with the hypothesis that education assists individuals in effectively deciding equivalent luminosity when moving from ILs to CFLs. Luminosity increases in transitions from IL to CFL bulbs are also found to be greater in larger (more than 2 person) households which presumably have greater lighting needs and are willing to invest a greater share of electricity savings to meet those needs. The IL to CFL selectivity correct coefficient (m12) is again significant $(p=0.10)$, implying in this 
case that there is correlation in the unobserved heterogeneity in the IL to CFL bulb choice and the CFL luminosity choice equation.

Even though descriptive statistics indicate that luminosity increases by 47 percent on average when ILs are replaced by LEDs, the IL to LED luminosity equation has little explanatory power and the F-test for overall significance of the model is rejected at conventional significance levels. In fact, the only variable showing statistical significance at conventional levels is the indicator for LEDs in bathrooms $(p=0.10)$. The small number of IL to LED transitions is one factor in the weak statistical performance of the model.

Change in bulb luminosity parameter estimates using the more parsimonious Lee selectivity correction model are presented in table A.2. For IL to IL bulb replacements the results look fairly similar overall. The two exceptions being that female respondents tend to increase bulb luminosity relative to males $(p=0.10)$ and older respondents tend to decrease bulb luminosity relative to those 27 to 65 years of age $(p=0.10)$. There is less similarity in the Lee results and the Dubin-McFadden results for changes in luminosity with IL to CFL bulb replacements. While the parameter estimate for taking the new bulb from storage is still large and negative, it is no longer statistically significant when the Lee selectivity correction method is employed. Similarly, stating energy efficiency as an important bulb attribute is no longer associated with increased luminosity in IL to CFL transitions. On the other hand, luminosity changes with IL to CFL transitions are now significantly lower when light quality is stated as an important bulb attribute. More associations are also found with respondent characteristics. Specifically, female respondents tend to increase bulb luminosity more than males, while the elderly show a lower increase than those 27 to 65 years of age. Large (more than 2 person) households no longer show significant increases in luminosity compared to single person households when IL bulbs are replaced with CFLs. 
The more parsimonious Lee selectivity correction model appears to perform slightly better than the Dubin-McFadden model in terms of significant parameter estimates with the small sample of IL to LED transitions. The large positive coefficient associated with lamp replacement is now statistically significant. Further, the selectivity correction coefficient is now negative and significant.

OLS parameter estimates without any selectivity correction are presented in table A.3. Again, the model F-tests and adjusted R-squared results suggest the three equations explain little of the observed variance in changes in bulb luminosity. Parameter estimates are different than those presented in the Dubin-McFadden and Lee results, particularly for the IL to IL luminosity change equation. Since selectivity correction coefficients are significant in both the DubinMcFadden and Lee models, the OLS results serve to highlight how incorrect inferences may arise when sample selection issues are not controlled for in estimation. For instance, we would conclude that taking IL bulbs from storage tends to lead to the use of higher luminosity IL bulbs.

\section{DISCUSSION AND POLICY IMPLICATIONS}

Observed household decisions with respect to bulb-type and luminosity choices are generally consistent with expected responses to the economic incentives generated by energy efficient bulbs. Several factors significantly impact household transitions from ILs to CFLs and to LEDs. Of particular note is the EU ban on IL bulbs. Households show a significant differential increase in the propensity to replace ILs that have banned wattage levels in 2012 relative to non-banned bulbs. On the other hand, storage of bulbs significantly slows transitions from ILs to more energy efficient lighting. Storage does not necessarily imply households are hoarding bulbs to avoid having to transition to less preferred CFLs or LEDs. Households may have stored IL bulbs in order to take advantage of bulk purchase discounts or sales, or to avoid fixed costs of purchase every time a bulb needs replacement. But in Germany some evidence of hoarding behavior does exist. Regardless of motivation, bulb storage appears to substantially lengthen the timeframe for 
transitions to new energy efficient technologies. Engineering estimates, projected future costs, and market trends all suggest that CFLs are only a transitionary technology and should lose significant future market share to more efficient LEDs. However, the impact of bulb storage on future CFL to LED transitions is likely to be even greater than that observed for IL to CLF transitions, as bulb life of CFLs is much greater than ILs.

Policy options to mitigate the negative impacts of storage on transitions to more energy efficient lighting include bulb buy-back programs or bulb credits towards new technology bulbs. In the case of future CFL to LED transitions, buy-back programs will also provide a mechanism to address disposal issues associated with mercury in CFLs. Households are found to be much more likely to adopt LEDs when fixtures are replaced than when bulbs are replaced, in part because new fixtures take full advantage of the small sizes and lower heat levels of LEDs. Programs to foster transitions to more energy efficient lighting may also focus on providing incentives for lighting fixture replacement rather than bulb replacement. However, as noted, the most common incentives to date have been to either provide new energy efficient bulbs for free or at a highly subsidized price.

Bulb attributes also matter in generating transitions to energy efficient lighting. Stated importance of energy efficiency motivates consumer transitions, as does environmental friendliness and durability. Interestingly, stated importance of light quality does not deter transitions from ILs to CFLs. However, preferences for light 'quality' do foster transitions from ILs to LEDs. Thus, it appears that consumers will be responsive to future efforts to convey the beneficial attributes of energy efficient bulbs. As regulations already require a significant amount of information on the label, focus, emphasis, and placement of information may be key for label effectiveness and should be explored further through focus groups. It is also worth noting that education is not a major factor in determining bulb choice. This result suggests differential access to information that is commonly associated with education level may not be a major constraint in the transition 
to energy efficient bulbs. Alternatively, the lack of significance of education may stem from the fact that by 2012 CFL bulbs were a well know technology and fairly widely diffused throughout the population. Early adopters tend to have higher education levels, but the characteristics of late adoptors are more diffuse (Rogers 2003). Price, as an important stated attribute, also does not influence IL to CFL and IL to LED transitions. Thus, higher up front CFL and LED costs may not be a significant barrier to adoption if information constraints are addressed.

Descriptive statistics show a large rebound effect stemming from luminosity increases in transitions from IL to CFL and to LED bulbs. When an IL bulb is replaced with another IL, luminosity is virtually unchanged. However, luminosity increases by 23 percent on average when ILs are replaced by CFLs and by 47 percent on average when ILs are replaced by LEDs. Luminosity changes do not completely capture the rebound effect, as more difficult to measure changes in bulb burn-time may also occur. However, the fact that this component of the rebound effect increases with bulb efficiency suggests that consumers rationally invest part of their energy cost savings from energy efficient bulbs in increased lumens to meet unsatiated lighting needs. If individuals are making informed decisions to purchase more lumens with per-lumen costs decreases associated with the new technology, then policies to curtail the rebound effect are unlikely to increase household welfare. By the same token, energy-savings will be substantially less than anticipated based strictly on comparisons of bulb efficiency. Large luminosity rebound effects are also consistent with Fouquet and Pearson's (2012) price elasticity of lighting demand estimates of around -0.5 for the early twenty-first century.

The current EU "Labelling Directive" 92/75/EEC requires the label on the packaging of bulbs to also include the luminous flux of the lamp in lumens, the input power (wattage) and the average rated life of the lamp, but households may still suffer from lack of information or bounded rationality when making purchase decisions. As argued by the European Commission (2011a, 2001b), the information provided on the package is often poorly explained or even mis- 
leading (e.g. equivalence claims about the light output). Likewise, consumers may not understand the various technical properties, or lack the capabilities to evaluate luminosity of alternative bulb types. Hence, even under perfect information, households may exhibit satisficing behaviour by choosing the closest acceptably (rather than utility maximizing) option or by using routines or rules of thumb (Simon, 1959). For example, the change in wattage of an IL from 50W to 60W seems a lot larger than a change in a LED from $9 \mathrm{~W}$ to $11 \mathrm{~W}$ and households may act on a "rather be safe than sorry" basis in thinking the move from $9 \mathrm{~W}$ to only $11 \mathrm{~W}$ is inconsequential. However, the change in lumen is actually much larger for the latter. Luminosity changes may also depend on the cost of search for accurate information on the performance of alternative bulbs. Search costs may be lower for more educated households, as education lowers the costs associated with the acquisition of information (Schultz 1975). The results do provide some evidence that information constraints play a role in observed bulb luminosity changes, as luminosity increases associated with IL to CFL transitions are lower at higher levels of education.

If information on equivalent bulb wattage is lacking or if individuals use bounded rationality in making bulb luminosity decisions then informational interventions may improve household welfare. New packaging guidelines that require the equivalent wattage of the three major bulb types to be prominently displayed may be one effective intervention. However, difficulties comparing luminosity base on wattage may also be a transitional problem. Younger generations are likely to become used to multiple bulb technologies and view luminosity, not wattage, as the appropriate benchmark. It is worth noting that bulb storage, while deterring transitions from ILs to more energy efficient lighting, mitigates luminosity increases associated with bulb transitions. Thus, bulb buy-back programs should also consider provisions to ensure matching luminosity of old and new bulbs.

Finally, the results indicate that most of the large average increases in luminosity with bulb transitions, particularly LEDs, remain unexplained. In fact, simulations of expected luminosity 
increases based on model parameter estimates and mean (or modal) variable values suggest that for both CFLs and LEDs the portion of the luminosity rebound associated with observed characteristics is rather small. Unobserved heterogeneity that is also associated with bulb choice appears to be the driving factor in relatively large observed luminosity rebounds associated with the transition to energy efficient bulbs. Further research is needed to identify key factors underlying this unobserved heterogeneity that make some households particularly likely to both adopt energy efficient bulbs and increase bulb luminosity. As noted, CFLs are very likely a transitional technology and, thus, future research should also increasingly focus on understand and fostering transitions to LEDs and other emerging potentially dominant lighting technologies.

\section{CONCLUSIONS}

Factors associated with household decisions to replace ILs with energy efficient CFLs or LEDs are examined in this paper, along with associated changes in bulb luminosity. Three key questions are addressed. 1) Did the ban appreciably increase the rate of adoption of energy efficient CFL and LEDs? 2) What other factors are associated with the switch from ILs to energy efficient lamps? 3) What are the factors associated with increases in lamp luminosity observed with the changeover to energy efficient lamps? Results suggest that the EU ban on ILs was effective in hastening transitions from ILs to more energy efficient CFL and LED bulbs. However, concerns about the reliance on changes in transition propensities from pre-2012 recall data do temper confidence in the result. Other factors also influence transitions for ILs to CFLs and LEDs. Of note, home storage of bulbs deterred such transitions, while consumer preferences for certain CFL and LED attributes - energy efficiency, environmental friendliness, and durability fostered transitions. But most household member characteristics are not strongly correlated with propensities to switch to energy efficient bulbs.

Luminosity increases associated with transitions to energy efficient bulbs are found to be large; 23 percent on average for IL to CFL transitions and 47 percent for IL to LED transitions. 
The taking of replacement bulbs from storage consistently mitigates luminosity increases. But the remaining variation in observed luminosity increases during transitions to energy efficient bulbs is largely unexplained and an important area for further research.

Study results, while specific to Germany, do have implications for the EU and beyond. Within the EU, Germany appears to be in the middle range of countries in terms of CFL bulb adoption (Mills and Schleich, 2012). This suggests that the impact of the IL ban may be broadly similar in aggregate across the wider array of EU countries. Further, preferences for energy efficient technologies appear to vary widely across countries and be correlated with energy efficient technology adoption. Thus there may be room to expand adoption by shaping preferences for energy efficiency, particularly in eastern European countries where base preferences for energy efficient technologies are low. However, Mills and Schleich (2012) also caution that the substantial cross-country heterogeneity in CFL and other residential energy efficient technology uptake within the EU implies the need to balance broader regional EU policies with policies that address country specific constraints to adoption.

Bulbs are also unique among resident energy efficient technologies, in that even the most expensive common LEDs are relatively inexpensive compared to white appliances and other common residential energy efficient technologies. Thus it is not surprising that some findings common to more capital-intensive technologies, like the deterrent affect of home rental on energy efficient technology adoption, do not hold. However, the results do imply bans on relatively inefficient traditional technologies and efforts to shape preferences for broader energy efficient technologies may be an option to increase adoption across an array of energy efficient technologies. 


\section{LITERATURE}

Allcott, H., S. Mullainathan, and Taubinsky, D. (2012). Externalities, Internalities, and the Targeting of Energy Policy. National Bureau of Economic Research Working Paper Number 17977. Cambridge, MA.

Bertoldi, P; Hirl, B. and Labanca, N. (2012). Energy Efficiency Status Report 2012 - electricity Consumption and Efficiency Trends in the EU-27. European Commission Joint Research Centre Institute for Energy and Transport, Ispra, Italy.

Borenstein, S. (2013). A Microeconomic Framework for Evaluating Energy Efficiency Rebound and Some Implications. National Bureau of Economic Research Working Paper Number 19044. Cambridge, MA.

Bourguignon, F., Fournier, M., and Gurgand, M. (2007). Selection Bias Corrections Based on the Multinomial Logit Model: Monte Carlo Comparisons. Econometrica 21(1): 174-205.

Brookes, L. (1990). The greenhouse effect: the fallacies in the energy efficiency solution. Energy Policy 18(2): 199-201.

CLASP (2013). Estimating potential additional energy savings from upcoming revisions to existing regulations under the ecodesign and energy labelling directives: a contribution to the evidence base. Report published 18. February 2013.

Chitnis, M., Sorrell, S., Druckman, A., Firth, S.K., Jackson, T. (2013). Turning lights into flights: Estimating direct and indirect rebound effects for UK Households. Energy Policy 55: 234250.

Davis L.W. (2012). "Evaluating the Slow Adoption of Energy Efficient Investments: Are Renters Less Likely to Have Energy Efficient Appliances?", in: The Design and Implementation of U.S. Climate Policy. Don Fullerton and Catherine Wolfram, eds. University of Chicago Press: Chicago. 
de Almeida, A. (2008). Residential Monitoring to Decrease Energy Use and Carbon Emissions in Europe (REMODECE). Deliverable D9: Report with the results of the surveys based on questionnaires for all countries. Downloaded from:www.isr.uc.pt/ remodece.

de Almeida, A.,, Zissis, G., Quicheron, M., Bertoldi, P. (2013). Accelerating the deployment of solit state lighting (SSL) in Europe, Joint Research Center, European Union..

di Maria, C., Ferreira, S. and Lazarova, E. (2010). Shedding Light on the Light Bulb Puzzle: the Role of Attitudes and Perceptions in the Adoption of Energy Efficient Light Bulbs, $\underline{\text { Scottish }}$ Journal of Political Economy 57(1): 48-67,.

Dubin, J.A. and McFadden, D.L. (1984). An econometric analysis of residential electrical appliance holdings and consumption. Econometrica 52(2): 345-362.

European Commission (2011a). Green Paper: Lighting the Future, Accelerating the deployment of innovative lighting technologies. The European Commission, Brussels, 15.12.2011, $\operatorname{COM}(2011) 889$ final.

European Commission (2011b). European Commission, Joint Research Centre, European LED Quality Charter, February 2011

Fouquet, R., Pearson, P.J.G, (2012). The long run demand for lighting: elasticities and rebound effects in different phases of economic development. Economics of Energy and Environmental Policy 1(1): 83-100.

Fouquet R., Pearson P.J.G. (2006). Seven Centuries of Energy Services: the Price and Use of Light in the United Kingdom (1300-2000). Energy Journal 27(1):139-177.

Frondel, M., Peters, J. and Vance C. (2008). Identifying the Rebound: Evidence from a German Household Panel. Energy Journal 29 (4): 154-163.

Frondel, M.and Lohmann, S. (2011). The European Commission's light bulb decree: Another costly regulation? Energy Policy 39: 3177-3181. 
Gillingham, K., Harding, M., and D. Rapson (2012). Split Incentives in Residential Energy Consumption. Energy Journal 33(2): 37-62.

Greening, L.A., Greene, D. L., Difiglio, C. (2000). Energy efficiency and consumption - the rebound effect - a survey. Energy Policy 28 (6): 389-401.

Heckman, J.J. (1979). Sample selection as a specification error. Econometrica 47(1): 153-161.

IEA (2010). Phase out of ILs. Implications for international supply and demand for regulatory compliant lamps. Information Paper. OECD/IEA, Paris.

IEA (2012). http://mappingandbenchmarking.iea-4e.org/ (IEA 18 February 2013).

Kanter, J. "Europe's Ban on Old-Style Bulbs Begins". New York Times. July 31, 2009. http://www.nytimes.com/2009/09/01/business/energy-environment/01iht-bulb.html

Khazzoom, J.D. (1980). Economic implications of mandated efficiency in standards for household appliances. Energy Journal 1(4): 21-40.

Khazzoom J.D. (1987). Energy savings resulting from the adoption of more efficient appliances. Energy Journal 8(4): 85-89.

Khazzoom J.D. (1989). Energy savings from more efficient appliances: a rejoinder. Energy Journal 10(1): 157-166.

Kumar, A., S.K. Jain, and N.K. Bansal (2003). Disseminating Energy-Efficient Technologies: A Case Study of Compact Fluorescent Lamps in India. Energy Policy 31: 59-272.

Lee, L.F. (1983). Generalized econometric models with selectivity. Econometrica 51(2): 507-512. McKinsey (2012). Lighting the way: Perspectives on the global lighting market. $2^{\text {nd }}$ Edition, August 2012. McKinsey\&Company.

Madlener, R., and Alcott, B. (2009). Energy rebound and economic growth: A review of the main issues and research needs. Energy 34: 370-376.

Mills, B. and J. Schleich (2009). Profits or Preferences? Assessing the Adoption of Residential Solar Thermal Technologies. Energy Policy 37(10): 4145-4154. 
Mills, B. and Schleich, J. (2010). Why Don't Households See the Light? Explaining the Diffusion of Compact Fluorescent Lamps. Resource and Energy Economics 32(3): 363-378.

Mills, B. and J. Schleich (2012). Residential energy-efficient technology adoption, energy conservation, knowledge, and attitudes: An analysis of European countries. Energy Policy 49: 616-628.

Rogers, E.M. (2003). Diffusion of Innovations. Free Press: New York.

Schleich, J., Mills, B., and Dütschke, E. (2014). Is the Future Always Brighter? Quantifying the Rebound Effect in Energy Efficient Lighting. Energy Policy 72: 35-42

Scott. S. (1997). Household Energy Efficiency in Ireland: A Replication Study of Ownership of Energy Saving Items. Energy Economics 19: 187-208.

Schultz, T.W. (1975). The Value of the Ability to Deal with Disequilibrium. Journal of Economic Literature 13(3): 827-46.

Simon, H.A. (1959). Theories of decision-making in economics and behavioural science. American Economic Review 49:253-283.

Sorrell, S. (2007). The rebound effect: An assessment of the evidence for economy-wide energy savings from improved energy efficiency. A report produced by the Sussex Energy Group for the technology and policy assessment function of the UK Energy Research Centre. Sussex: UK Energy Research Centre.

Spiegel Online International. "Getting Around the EU Ban: Germans Hoarding Traditional Light Bulbs.” July 27, 2009. http://www.spiegel.de/international/germany/getting-around-the-euban-germans-hoarding-traditional-light-bulbs-a-638494.html

van den Bergh, J. C. J. M. (2011). Energy conservation more effective with rebound policy. Environmental \& Resource Economics 48: 43-58. 
VITO, 2009. Preparatory Studies for Eco-design Requirements of EuPs. Final report Lot 19: Domestic lighting, October 2009. 
Table 1. Replacement Bulb Choice by Type

\begin{tabular}{lrrrrr}
\multicolumn{7}{l}{ Replacement Type } \\
\cline { 3 - 6 } Initial Bulb & IL & CFL & LED & \multicolumn{1}{l}{ Total All } \\
\cline { 1 - 5 } IL & 996 & 601 & 117 & 1,714 \\
CFL & 73 & 1053 & 82 & 1,208 \\
LED & 0 & 6 & 100 & 106 \\
\hline
\end{tabular}

Note: Sample includes broken and burned out, non-broken, and fixture replacement bulbs. 
Table 2. Descriptive Statistics

\begin{tabular}{|c|c|c|c|}
\hline Variable & Description & $\begin{array}{l}\text { Bulb Type Data } \\
(\mathrm{N}=1,714) \\
\text { Mean }\end{array}$ & $\begin{array}{l}\text { Luminosity Data } \\
(\mathrm{N}=1,660) \\
\text { Mean }\end{array}$ \\
\hline IL to IL & IL to IL transition (share) & 0.581 & \\
\hline IL to $C F L$ & IL to CFL transition (share) & 0.351 & \\
\hline IL to LED & IL to LED transition (share) & 0.068 & \\
\hline fluxratio & Ratio luminosity new to initial bulb & & 1.101 \\
\hline time12 & Bulb replaced in $2012=1$ & 0.735 & \\
\hline bantime & Bulb replaced $2012 \&$ banned $=1$ & 0.124 & \\
\hline lamp & Replacement lamp $=1$ & 0.054 & 0.051 \\
\hline storage & Replacement bulb from storage $=1$ & 0.613 & 0.623 \\
\hline main & Bulb used for main lighting $=1$ & 0.668 & 0.669 \\
\hline living & Bulb in living/dining room (base) & 0.279 & 0.274 \\
\hline bedrm & Bulb in bedroom $=1$ & 0.086 & 0.085 \\
\hline kitcrm & Bulb in kitchen $=1$ & 0.121 & 0.123 \\
\hline hallrm & Bulb in hallway $=1$ & 0.190 & 0.192 \\
\hline childrm & Bulb in child's room $=1$ & 0.023 & 0.022 \\
\hline bathrm & Bulb in bathroom $=1$ & 0.162 & 0.160 \\
\hline otherrm & Bulb in other room $=1$ & 0.107 & 0.110 \\
\hline outdoor & Bulb outdoors $=1$ & 0.033 & 0.034 \\
\hline rent & Rent home $=1$ & 0.450 & \\
\hline price & Price a listed criteria $=1$ & 0.547 & 0.544 \\
\hline quality & Quality a listed criteria $=1$ & 0.517 & 0.517 \\
\hline electuse & Energy efficiency a listed criteria $=1$ & 0.598 & 0.599 \\
\hline durable & Durability a listed criteria $=1$ & 0.522 & 0.523 \\
\hline environ & Environmental friendly listed criteria $=1$ & 0.228 & 0.228 \\
\hline dimmable & Dimmabilty a listed criteria $=1$ & 0.061 & \\
\hline low & High school or less (base) & 0.215 & 0.219 \\
\hline middle & Technical school $=1$ & 0.485 & 0.481 \\
\hline high & University=1 & 0.299 & 0.299 \\
\hline female & Female respondent $=1$ & 0.402 & 0.395 \\
\hline young & 16 to 26 years of age $=1$ & 0.058 & 0.054 \\
\hline elderly & 65 years of age or older $=1$ & 0.183 & 0.187 \\
\hline single & Single person household (base) & 0.274 & 0.275 \\
\hline twopers & Two person household=1 & 0.423 & 0.425 \\
\hline twoplus & Two plus person household $=1$ & 0.303 & 0.299 \\
\hline
\end{tabular}


Table 3: Multinomial Logit Relative Risk Ratio Estimates

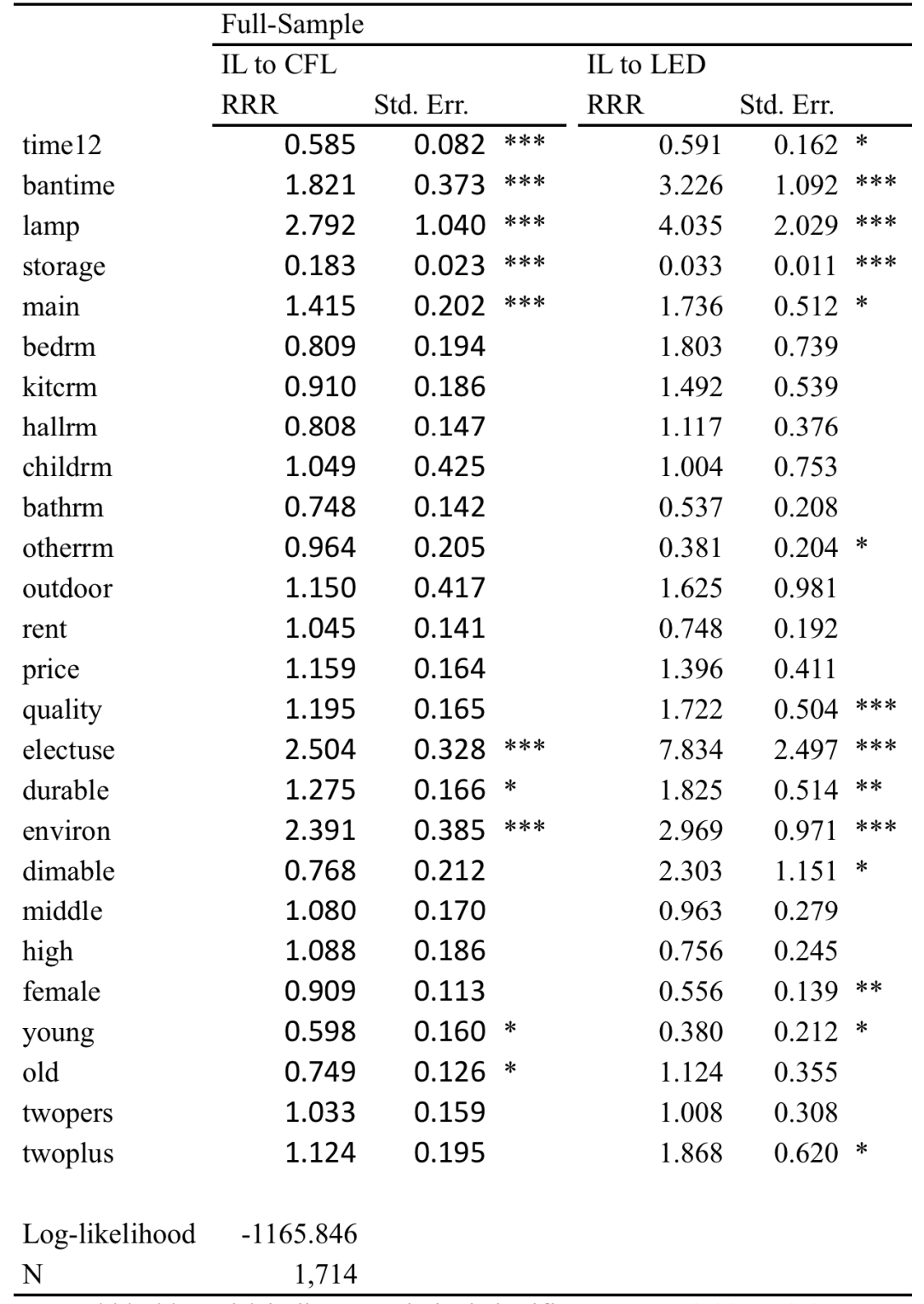

Note: ${ }^{* * *}, * *$, and $*$ indicate statistical significance at $\mathrm{p}=0.01, \mathrm{p}=0.05$, and $\mathrm{p}=0.1$ levels in two-tailed $\mathrm{t}$-tests, respectively. 
Table 4: Bulb Luminosity Change Estimates, Dubin-McFadden Method with Bootstrap (N=500)

\begin{tabular}{|c|c|c|c|c|c|c|c|c|c|}
\hline & \multicolumn{3}{|l|}{ IL to IL } & \multicolumn{3}{|l|}{ IL to CFL } & \multicolumn{3}{|l|}{ IL to LED } \\
\hline & Coef. & Std. Err. & & Coef. & Std. Err. & & Coef. & Std. Err. & \\
\hline lamp & 0.164 & 0.131 & & 0.289 & 0.258 & & 1.169 & 0.875 & \\
\hline storage & -0.176 & 0.063 & $* * *$ & -0.936 & 0.303 & $* * *$ & -1.110 & 1.050 & \\
\hline main & 0.060 & 0.024 & $* *$ & 0.141 & 0.111 & & 0.253 & 0.556 & \\
\hline bedrm & 0.010 & 0.041 & & 0.055 & 0.193 & & -0.004 & 0.513 & \\
\hline kitcrm & 0.020 & 0.026 & & 0.026 & 0.137 & & 0.018 & 0.433 & \\
\hline hallrm & 0.006 & 0.026 & & 0.109 & 0.133 & & 0.495 & 0.462 & \\
\hline childrm & 0.068 & 0.057 & & -0.078 & 0.250 & & 0.865 & 1.034 & \\
\hline bathrm & 0.011 & 0.030 & & 0.005 & 0.151 & & -0.837 & 0.499 & $*$ \\
\hline otherrm & 0.002 & 0.037 & & -0.199 & 0.149 & & -0.604 & 0.777 & \\
\hline outdoor & 0.005 & 0.071 & & -0.102 & 0.190 & & 0.048 & 0.672 & \\
\hline price & 0.011 & 0.021 & & 0.012 & 0.096 & & -0.115 & 0.271 & \\
\hline quality & 0.002 & 0.019 & & -0.103 & 0.093 & & -0.275 & 0.329 & \\
\hline electuse & 0.091 & 0.037 & $* *$ & 0.334 & 0.167 & $* *$ & 0.461 & 0.585 & \\
\hline environ & 0.076 & 0.037 & $* *$ & 0.196 & 0.139 & & -0.068 & 0.435 & \\
\hline middle & 0.006 & 0.024 & & -0.132 & 0.118 & & 0.323 & 0.325 & \\
\hline high & -0.014 & 0.024 & & -0.228 & 0.117 & $*$ & 0.137 & 0.413 & \\
\hline female & 0.025 & 0.020 & & 0.061 & 0.091 & & -0.132 & 0.369 & \\
\hline young & -0.067 & 0.039 & $*$ & 0.128 & 0.254 & & -0.962 & 0.634 & \\
\hline elderly & -0.042 & 0.028 & & -0.169 & 0.105 & & 0.299 & 0.419 & \\
\hline twopers & -0.002 & 0.020 & & 0.115 & 0.098 & & 0.080 & 0.339 & \\
\hline twoplus & -0.002 & 0.025 & & 0.254 & 0.117 & $* *$ & 0.626 & 0.434 & \\
\hline M11 & -0.074 & 0.085 & & -0.932 & 0.835 & & -0.758 & 2.032 & \\
\hline M12 & 0.329 & 0.181 & $* *$ & 0.310 & 0.172 & $*$ & -1.474 & 2.103 & \\
\hline M13 & 0.338 & 0.269 & & 1.105 & 0.763 & & 0.589 & 0.452 & \\
\hline constant & 1.217 & 0.106 & $* * *$ & 0.664 & 0.633 & & -1.837 & 1.990 & \\
\hline Sigma2 & 0.167 & 0.134 & & 2.064 & 1.953 & & 3.385 & 10.183 & \\
\hline F-Test & 2.090 & $* * *$ & & 2.020 & $* * *$ & & 1.170 & & \\
\hline Adj. $R^{\wedge} 2$ & 0.026 & & & 0.043 & & & 0.036 & & \\
\hline $\mathrm{N}$ & 996 & & & 553 & & & 111 & & \\
\hline
\end{tabular}

Note: $* * *, * *$, and $*$ indicate statistical significance at the $\mathrm{p}=0.001, \mathrm{p}=0.05$, and $\mathrm{p}=0.1$ levels in two-tailed t-tests, respectively. 
Table A.1: Translation of Bulb Purchase Criteria Question

Bulb Purchase Criteria: What are your three most important criteria when purchasing a light bulb? (Response items are randomized).

- Price

- Producer/Brand

- Form/Shape

- Quality of light (spectrum, color, flickering, etc.)

- Convenient disposal

- Electricity use/Energy efficiency

- Lifespan

- Environmental friendliness

- Dimmability

- $\quad$ Rating in test reports. 
Table A.2: Bulb Luminosity Change Estimates, Lee Method with Bootstrap ( $N=500)$

\begin{tabular}{|c|c|c|c|c|c|c|c|c|c|}
\hline & $\begin{array}{l}\text { IL to IL } \\
\text { Coef. }\end{array}$ & Std. Err. & & $\begin{array}{l}\text { IL to CFL } \\
\text { Coef. }\end{array}$ & Std. Err. & & $\begin{array}{l}\text { IL to LED } \\
\text { Coef. }\end{array}$ & Std. Err. & \\
\hline lamp & 0.183 & 0.129 & & -0.151 & 0.186 & & 1.121 & 0.669 & $*$ \\
\hline storage & -0.147 & 0.054 & $* * *$ & -0.232 & 0.164 & & -1.094 & 0.852 & \\
\hline main & 0.055 & 0.022 & $* *$ & 0.026 & 0.087 & & 0.243 & 0.520 & \\
\hline bedrm & 0.006 & 0.038 & & 0.011 & 0.162 & & -0.052 & 0.465 & \\
\hline kitcrm & 0.015 & 0.026 & & -0.019 & 0.114 & & -0.018 & 0.403 & \\
\hline hallrm & 0.004 & 0.024 & & 0.115 & 0.128 & & 0.456 & 0.412 & \\
\hline childrm & 0.067 & 0.049 & & -0.054 & 0.201 & & 0.875 & 0.926 & \\
\hline bathrm & 0.017 & 0.028 & & 0.134 & 0.123 & & -0.810 & 0.451 & $*$ \\
\hline otherrm & 0.010 & 0.033 & & -0.107 & 0.112 & & -0.574 & 0.717 & \\
\hline outdoor & 0.001 & 0.074 & & -0.221 & 0.143 & & 0.022 & 0.684 & \\
\hline price & 0.010 & 0.019 & & -0.013 & 0.081 & & -0.106 & 0.271 & \\
\hline quality & -0.001 & 0.018 & & -0.166 & 0.078 & $* *$ & -0.273 & 0.325 & \\
\hline electuse & 0.072 & 0.029 & $* *$ & -0.034 & 0.105 & & 0.435 & 0.471 & \\
\hline environ & 0.071 & 0.031 & $* *$ & -0.019 & 0.102 & & -0.044 & 0.311 & \\
\hline middle & 0.005 & 0.023 & & -0.111 & 0.109 & & 0.338 & 0.285 & \\
\hline high & -0.012 & 0.024 & & -0.196 & 0.100 & $* *$ & 0.159 & 0.388 & \\
\hline female & 0.030 & 0.018 & $*$ & 0.168 & 0.076 & $* *$ & -0.113 & 0.340 & \\
\hline young & -0.059 & 0.033 & $*$ & 0.328 & 0.222 & & -0.954 & 0.617 & \\
\hline elderly & -0.045 & 0.024 & $*$ & -0.172 & 0.080 & $* *$ & 0.269 & 0.354 & \\
\hline twopers & -0.004 & 0.020 & & 0.093 & 0.085 & & 0.064 & 0.305 & \\
\hline twoplus & -0.009 & 0.022 & & 0.135 & 0.105 & & 0.587 & 0.411 & \\
\hline $\mathrm{m} i$ & 0.300 & 0.084 & $* * *$ & -0.270 & 0.254 & & -1.298 & 0.650 & $* *$ \\
\hline constant & 1.152 & 0.077 & $* * *$ & 1.183 & 0.311 & $* * *$ & -1.251 & 1.558 & \\
\hline Sigma2 & 0.071 & 0.013 & $* * *$ & 0.769 & 0.217 & $* * *$ & 7.331 & 7.511 & \\
\hline F-Test & 2.170 & $* * *$ & & 1.620 & $* *$ & & 1.150 & & \\
\hline Adj. $R^{\wedge} 2$ & 0.025 & & & 0.024 & & & 0.048 & & \\
\hline $\mathrm{N}$ & 996 & & & 553 & & & 111 & & \\
\hline
\end{tabular}


Table A.3: Bulb Luminosity Change Estimates, OLS

\begin{tabular}{|c|c|c|c|c|c|c|c|c|c|}
\hline & \multicolumn{3}{|l|}{ IL to IL } & \multicolumn{3}{|l|}{ IL to CFL } & \multicolumn{3}{|l|}{ IL to LED } \\
\hline & Coef. & Std. Err. & & Coef. & Std. Err. & & Coef. & Std. Err. & \\
\hline lamp & 0.001 & 0.069 & & -0.206 & 0.146 & & 0.505 & 0.378 & \\
\hline storage & 0.036 & 0.019 & $* *$ & -0.084 & 0.078 & & 0.207 & 0.376 & \\
\hline main & 0.024 & 0.017 & & 0.001 & 0.090 & & -0.087 & 0.323 & \\
\hline bedrm & 0.017 & 0.028 & & 0.034 & 0.148 & & -0.483 & 0.395 & \\
\hline kitcrm & 0.024 & 0.025 & & -0.011 & 0.122 & & -0.231 & 0.329 & \\
\hline hallrm & 0.023 & 0.022 & & 0.133 & 0.113 & & 0.320 & 0.314 & \\
\hline childrm & 0.073 & 0.053 & & -0.075 & 0.244 & & 0.764 & 0.735 & \\
\hline bathrm & 0.044 & 0.023 & $*$ & 0.145 & 0.116 & & -0.537 & 0.381 & \\
\hline otherrm & 0.015 & 0.026 & & -0.130 & 0.127 & & -0.130 & 0.545 & \\
\hline outdoor & -0.025 & 0.043 & & -0.229 & 0.209 & & -0.365 & 0.538 & \\
\hline price & 0.006 & 0.016 & & -0.022 & 0.082 & & -0.062 & 0.233 & \\
\hline quality & -0.009 & 0.016 & & -0.177 & 0.080 & $* *$ & -0.257 & 0.272 & \\
\hline electuse & -0.011 & 0.015 & & -0.104 & 0.085 & & -0.189 & 0.339 & \\
\hline environ & -0.003 & 0.021 & & -0.090 & 0.088 & & -0.075 & 0.273 & \\
\hline middle & -0.003 & 0.019 & & -0.119 & 0.095 & & 0.480 & 0.270 & $*$ \\
\hline high & -0.014 & 0.020 & & -0.206 & 0.104 & $* *$ & 0.412 & 0.295 & \\
\hline female & 0.045 & 0.015 & $* * *$ & 0.171 & 0.076 & $* *$ & 0.143 & 0.250 & \\
\hline young & -0.022 & 0.030 & & 0.352 & 0.193 & $*$ & -0.780 & 0.532 & \\
\hline elderly & -0.031 & 0.019 & $*$ & -0.144 & 0.103 & & 0.171 & 0.318 & \\
\hline twopers & -0.001 & 0.018 & & 0.100 & 0.088 & & -0.095 & 0.306 & \\
\hline twoplus & -0.015 & 0.020 & & 0.145 & 0.098 & & 0.179 & 0.303 & \\
\hline constant & 0.921 & 0.035 & $* * *$ & 1.464 & 0.168 & $* * *$ & 1.440 & 0.625 & $* *$ \\
\hline F-Test & 1.380 & & & 1.640 & & $* *$ & 1.050 & & \\
\hline Adj. $R^{\wedge} 2$ & 0.008 & & & 0.024 & & & 0.009 & & \\
\hline $\mathrm{N}$ & 996 & & & 553 & & & 111 & & \\
\hline
\end{tabular}

